\title{
Lung cancer mortality in a cohort of UK cotton workers: an extended follow-up
}

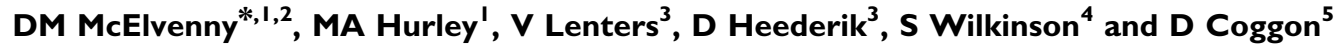 \\ 'School of Health, University of Central Lancashire, Preston, Lancashire, PRI 2HE, UK; ${ }^{2}$ Statistics and Health Limited, 12 Turfnell Way, Worsley, \\ Manchester, M28 2PZ, UK; ${ }^{3}$ Institute for Risk Assessment Sciences, Division of Environmental Epidemiology, Utrecht University, Utrecht, NL-3508 TD, \\ The Netherlands; ${ }^{4}$ Epidemiology Group, Health \& Safety Executive, Bootle, Merseyside, L20 7HS, UK; ${ }^{5}$ MRC Lifecourse Epidemiology Unit, University \\ of Southampton, Southampton, SOI6 6YD, UK
}

BACKGROUND: A recent systematic review and meta-analysis suggested that occupational exposure to endotoxins protects against lung cancer. To explore this hypothesis further, the follow-up of mortality of a cohort of 355 I workers, who were employed in the British cotton industry during 1966-1971, was extended by 23 years.

METHODS: Subjects had originally been recruited to a survey of respiratory disease, which collected information about occupation and smoking habits. Cumulative exposures to endotoxins were estimated from data on endotoxin levels by work areas in cotton mills. Risks of lung cancer were estimated using survival modelling.

RESULTS: During follow-up, 2018 deaths were recorded before the age of 90 years, including 128 deaths from lung cancer. After adjustment for smoking, hazard ratios (95\% confidence intervals) for cumulative endotoxin exposures of $\leqslant 30000,>30000$ and $\leqslant 200000,>200000$ and $\leqslant 400000,>400000$ and $\leqslant 600000$ and $>600000$ endotoxin units (EU) $\mathrm{m}^{-3}$ years were I, 0.8 $(0.5-1.6), 0.7(0.4-1.3), 0.6(0.3-1.0)$ and $0.5(0.3-0.9)$, respectively $(P$ for trend $=0.005)$.

CONCLUSION: Our findings strengthen the evidence that occupational exposure to endotoxins protects against lung cancer, and suggest that the effect depends on cumulative dose and persists after exposure ceases.

British Journal of Cancer (201 I) 105, 1054-1060. doi:10.1038/bjc.2011.312 www.bjcancer.com

Published online 16 August 2011

(C) 201 I Cancer Research UK

Keywords: lung cancer; cotton; endotoxin

Endotoxins are the lipopolysaccharide component of the outer membrane of Gram-negative bacteria, and can be released to the environment during cell replication and lysis (Liebers et al, 2008). They are ubiquitous in indoor and outdoor environments, but the highest exposures occur in certain occupational settings such as agriculture and cotton textile mills (Liebers et al, 2006). Exposure occurs primarily through inhalation of airborne endotoxin present in organic dusts (Liebers et al, 2008).

The noncancer adverse health effects of acute and chronic exposure to endotoxins are well recognised. They include localised neutrophilic inflammation leading to respiratory symptoms and lung function decrements, and at very high doses, systemic inflammation leading to the organic dust toxic syndrome (Rylander, 2002). Endotoxins and their active component, lipid A, have exhibited antitumoural effects in animal models and have shown some encouraging results in phase I and phase II clinical trials (Reisser et al, 2002). A recent systematic review and metaanalysis of lung cancer risk in cotton textile workers found a significantly low summary relative risk (Lenters et al, 2010). Moreover, the relative risk was $<1.0$ for most subgroups of studies distinguished according to study time period, study design, whether the outcome was mortality or morbidity, whether or not

*Correspondence: Professor DM McElvenny;

E-mail: damien@statisticsandhealth.co.uk

Received I8 January 20 II; revised I 4 July 201 I; accepted 19 July 20 II; published online 16 August 2011 analysis included adjustment for smoking, geographical area and subjects' sex. Two studies in the systematic review provided quantitative estimates of endotoxin exposure and these indicated a dose-dependent protective effect against lung cancer risk (Astrakianakis et al, 2007; Kuzmickiene and Stukonis, 2007). Findings to date on endotoxin exposure and risk of malignancies other than lung cancer have been limited and inconsistent (Lundin and Checkoway, 2009).

One of the studies included in the recent meta-analysis of cotton textile workers focussed on a British cohort in which there was a statistically significant deficit of lung cancer for men and women combined among workers with $\geqslant 30$ years of service in the cotton industry (standardised mortality ratio $(\mathrm{SMR})=64,95 \%$ confidence interval (CI) 40-97, 22 deaths) (Hodgson and Jones, 1990). To explore further the possible protective effect of endotoxins in cotton dust on the risk of lung and other cancers, we updated the follow-up of this cohort, which had originally been assembled in the late 1960s and early 1970s. An important strength of the study was its data on potential confounding factors, and especially on cigarette smoking. We extended follow-up by 23 years, during which time some 1500 additional deaths were expected.

\section{MATERIALS AND METHODS}

\section{Study population}

Details of how the cohort was assembled have been published (Fox et al, 1973a, b; Hodgson and Jones, 1990). Subjects were originally 
recruited into a study of respiratory illness in a sample of 52 mills that spun coarse (39 mills), medium (11 mills) or fine (2 mills) cotton. Most of the mills were located in Lancashire (48), but two were in Yorkshire and two in Scotland. The mills were visited by a research team on two occasions between 1966 and 1970, and workers were eligible for the study if they were employed at a mill at the time of a visit, and were Caucasian in origin. Of the total population eligible for inclusion, $\sim 10 \%$ declined to participate. Between 1971 and 1974, many workers were visited again either at work or at their home address but no new subjects were recruited to the study.

At the time of recruitment, workers were interviewed, and a modified version of the UK Medical Research Council questionnaire on respiratory symptoms (Roach and Schilling, 1960) was used to collect data on symptoms and on factors that might influence their risk of respiratory disease. Among other things, participants were asked about their current job (job title and whether they worked full time or part time); when they had first worked in the cotton industry; their smoking habits (classified as nonsmoker, former smoker, and for current smokers according to the number of cigarettes smoked per day); and whether they had a cough or brought up phlegm on most days for at least 3 months of the year (Fox et al, 1973a). In addition, spirometry was performed, and temperature-corrected measurements of forced expiratory volume in $1 \mathrm{~s}\left(\mathrm{FEV}_{1}\right)$ were expressed as a percentage of predicted values derived from Cotes' equations (Cotes, 1968), taking into account sex, age and height (no suitable reference values were available for lung function in people of non-Caucasian ethnicity in the United Kingdom at that time - hence their exclusion).

Where participants had left the industry at the time of a subsequent visit by the research team ( $21 \%$ of subjects), their leaving date was recorded. Total duration of employment as a cotton worker was estimated from the year in which they first entered the industry and their leaving date, if recorded, with adjustment in a few cases for known periods of absence. Where the worker was still employed at the time of the last mill visit, it was assumed that he/she remained in the industry for one further year after that visit (British cotton mills were closing rapidly in the mid-1970s).

\section{Endotoxin exposure assessment}

From their job title at the time of recruitment, subjects were assigned to three work areas as in previous analyses (Fox et al, 1973a, b) - 'opening' (openers in the cotton chamber), 'carding' (carder, lap carrier, stripper and grinder, laptender, card tender, waste devil hole attendant, maintenance engineer) and 'ring room/ winding' (spinner overlooker, spinner doffer, doubler, winder and beamer pirn winder). A simple job-exposure matrix was then created, in which airborne endotoxin concentrations were assigned to the three work areas, according to whether the mill spun predominantly coarse/medium or fine cotton.

To determine endotoxin concentrations, a literature search was performed, and the authors of relevant papers were contacted, to seek quantitative data, both from the United Kingdom and elsewhere, on measured endotoxin levels in the cotton textile industry and parallel measurements of endotoxin and cotton dust. Raw endotoxin data were obtained for cotton mills in Lancashire (Niven, 1993; Simpson et al, 1999; Fletcher, 2003) and from other countries (China, Turkey and Germany; Astrakianakis et al, 2006; Oldenburg et al, 2007; Bakirci et al, 2007). Additional published data on historic measurements in the UK mills were considered (Roach and Schilling, 1960; Molyneux and Tombleson, 1970; Berry et al, 1973; Cinkotai et al, 1988; Fishwick et al, 1994). Endotoxin levels expressed as $\mathrm{ng} \mathrm{m}^{-3}$ were multiplied by 10 to approximate values in endotoxin units $(\mathrm{EU}) \mathrm{m}^{-3}$. The data corresponding to each of the three work areas of interest were collected, and median, arithmetic mean and geometric mean values were calculated from the raw data and extracted from other published data, when possible. Two of the team (VL and DH) then derived expert-based '(best) estimates' of average endotoxin levels by work area and type of mill, taking account of all available data, but giving greater weight to those from surveys performed in the United Kingdom (Niven, 1993; Simpson et al, 1999; Fletcher, 2003) (Table 1).

Individuals were assigned cumulative exposures to endotoxins (in $\mathrm{EU} \mathrm{m}^{-3}$ years) calculated as the product of the estimated airborne concentration for the area in which they worked at the time of recruitment and their estimated duration of employment in the cotton industry - that is, with the assumption that the person had worked in the same area throughout his/her career. An adjustment factor of 0.5 was applied to the employment times of part-time workers. Where a worker's job title was unrecorded $(n=179)$, endotoxin exposure could not be determined, and these individuals were therefore excluded from analyses relating to endotoxin exposure.

\section{Follow-up}

The cohort was followed for mortality to the end of 2007 through the National Health Service Central Register (NHSCR). Deaths were coded according to the eighth (ICD-8), ninth (ICD-9) or tenth (ICD-10) revisions of the International Classification of Diseases (ICD), depending on the year of death. The Supplementary Table 1 shows ICD codes for the disease categories that were analysed. These disease categories were chosen a priori on the basis of findings from earlier cohort studies of cotton textile workers (Henderson and Enterline, 1973; Wernli et al, 2003, 2006; Kuzmickiene et al, 2004; De Roos et al, 2005; Chang et al, 2006; Gold et al, 2006; Wong et al, 2006; Li et al, 2006a, b; Astrakianakis et al, 2007; Ray et al, 2007). Following checks against original paper records and data from the NHSCR, the number of workers whom we classed as traced differed slightly from that in the analysis that had been reported previously for the cohort (Hodgson and Jones, 1990). Sixteen workers from the original analysis were excluded because of doubtful trace information, and lost medical examination data were found in the paper records for 17 workers who had been traced. Thus, the overall cohort size was one larger than in the earlier analysis.

\section{Statistical analysis}

Person-years analyses were conducted using the software system $\mathrm{R}$ (Venables and Smith, 2010) to derive SMRs and their 95\% CIs. Expected numbers of deaths were calculated from national rates for England and Wales in 5-year age bands and single calendar year periods. Scottish rates were not used for the Scottish mills as there were only two of them. In addition, the SMRs were modelled within a survival modelling framework, in which it was assumed that deaths occurred at random but with a hazard of occurrence

Table I Estimates of endotoxin concentrations in cotton mill working areas according to predominant type of fibre processed

\begin{tabular}{llcc}
\hline Fibre type & Mill area & $\begin{array}{c}\text { No. of } \\
\text { workers }\end{array}$ & $\begin{array}{c}\text { Endotoxin } \\
\text { concentration } \\
\left(\mathbf{E U ~ m ~}^{-3} \mathbf{)}\right.\end{array}$ \\
\hline Coarse or medium & Opening & 335 & 18000 \\
& Carding & 2394 & 18000 \\
& Ring room/winding & 490 & 300 \\
Fine & Not known & 101 & - \\
& Opening & 2 & 9000 \\
& Carding & 22 & 9000 \\
& Ring room/winding & 37 & 150 \\
& Not known & 78 & - \\
\hline
\end{tabular}


that varied over time and was specific to the individual worker (Tom and Farewell, 2009).

Follow-up began at the date of entry to the study (i.e., first medical examination). For the main analyses, workers then contributed person-years at risk until the earliest of (1) date of death, (2) loss to follow-up (mainly through emigration), (3) 31 December 2007 or (4) age 90 years.

\section{Ethical considerations}

Ethical approval was provided by the Faculty of Health Ethics Committee at the University of Central Lancashire. The Patient Information Advisory Group of the Department of Health exempted the investigators from having retrospectively to obtain individual informed consent to inclusion in the study.

\section{RESULTS}

From a total cohort of 3551 workers for whom data from at least one medical examination were available, 3459 (97.4\%) were successfully traced at NHSCR (Table 2). Most had worked in the cotton industry for $>20$ years, the earliest such employment being in 1906. The most common area of work was carding. By the end of follow-up, 2159 cohort members had died, 141 after reaching 90 years of age. In all, 44 men $(2.8 \%)$ and 46 women $(2.4 \%)$ were lost to follow-up ( 2 of the women after age 90 ). The total number of person-years of follow-up was 99135 .

Table 3 summarises the mortality of the cohort in comparison with the general population of England and Wales. Total mortality was significantly higher than expected (SMR $=105,95 \%$ CI: $100-109$, 2018 deaths), largely because of high rates of circulatory and respiratory disease. Total cancer mortality was within the expected range (SMR $=99,95 \% \mathrm{CI}: 91-108,515$ deaths), as was that from lung cancer (SMR $=99,95 \%$ CI: $82-116,128$ deaths).

Table 4 shows SMRs for lung cancer according to smoking habits and estimated duration of work in the cotton industry. In both sexes, mortality from lung cancer was highest in moderate/ heavy smokers and lowest in lifelong nonsmokers. Moreover, within both light and moderate/heavy smokers, the risk of lung cancer tended to decline with longer duration of employment in the cotton industry, the trend being clearest in the analyses for both sexes combined.

The hazard ratio for death from lung cancer was modelled according to estimated cumulative exposure to endotoxins (classified to approximate fifths of its distribution in the cohort as a whole) while controlling for smoking habits (Table 5). Risk of lung cancer tended to decrease with higher cumulative exposure to endotoxins, the trend being statistically significant in men $(P=0.05)$ and in both sexes combined $(P=0.005)$. Among men and women combined, the overall hazard ratio in the highest relative to the lowest exposure category was 0.5 (95\% CI: 0.3-0.9). When risk estimates were adjusted also for $\mathrm{FEV}_{1}$ (\% predicted) and report of cough or phlegm at entry to the study, the trends in relation to endotoxin exposure were stronger, with an overall hazard ratio of 0.4 (95\% CI: $0.2-0.8)$ for the highest relative to the lowest endotoxin category. No such trends were apparent in similar analyses for the combination of all cancers other than lung cancer (data not shown).

Figure 1 shows the relation of endotoxin exposure to lung cancer mortality earlier and later in the period of follow-up. Again, risk estimates are adjusted for smoking habits. The decline in risk of lung cancer with increasing cumulative exposure to endotoxins was clearly apparent after 1987 as well as earlier in follow-up.

\section{DISCUSSION}

Our study adds further weight to the evidence for a protective effect of endotoxins against lung cancer. Moreover, it suggests that
Table 2 Characteristics of subjects included in the analysis

\begin{tabular}{|c|c|c|}
\hline Characteristic & $\begin{array}{c}\text { Men } \\
(n=1548)\end{array}$ & $\begin{array}{l}\text { Women } \\
(n=|9| I)\end{array}$ \\
\hline Age at I January 1966 (years) & $\begin{array}{c}\text { Number } \\
\text { (percentage) (\%) }\end{array}$ & $\begin{array}{c}\text { Number } \\
\text { (percentage) (\%) }\end{array}$ \\
\hline$<20$ & $266(17)$ & $102(5)$ \\
\hline $20-29$ & $219(14)$ & $196(10)$ \\
\hline $30-39$ & $278(18)$ & $406(21)$ \\
\hline $40-49$ & $293(19)$ & $536(28)$ \\
\hline $50-59$ & $365(24)$ & $568(30)$ \\
\hline $60-69$ & $118(8)$ & $94(5)$ \\
\hline$>70$ & $9(1)$ & $9(0.5)$ \\
\hline \multicolumn{3}{|l|}{ Characteristics at recruitment } \\
\hline \multicolumn{3}{|l|}{ Smoking status } \\
\hline Nonsmoker & $333(22)$ & $856(45)$ \\
\hline Light smoker ( 1 - I4 cigarettes per day) & $589(38)$ & $615(32)$ \\
\hline $\begin{array}{l}\text { Medium/heavy smoker ( } \geqslant 15 \\
\text { cigarettes per day) }\end{array}$ & $536(35)$ & $391(20)$ \\
\hline Former smoker & $90(6)$ & $49(3)$ \\
\hline \multicolumn{3}{|l|}{ Working area } \\
\hline Unknown & $47(3)$ & $132(7)$ \\
\hline Opening & $329(21)$ & $8(0)$ \\
\hline Carding & $1034(67)$ & $1382(72)$ \\
\hline Ring room/winding & $138(9)$ & $389(20)$ \\
\hline \multicolumn{3}{|l|}{ Working hours } \\
\hline Part time & $14(0.9)$ & $248(13)$ \\
\hline \multicolumn{3}{|l|}{ Cough or phlegm } \\
\hline Present & $508(33)$ & $493(26)$ \\
\hline \multicolumn{3}{|l|}{ FEV (\% predicted) } \\
\hline Mean (s.d.) & $90(19)$ & $93(19)$ \\
\hline Range & $10-168$ & $15-146$ \\
\hline \multicolumn{3}{|l|}{ Time worked in cotton industry (years) } \\
\hline $1-3$ & $193(12)$ & $73(4)$ \\
\hline $4-10$ & $286(18)$ & $226(12)$ \\
\hline||$-20$ & $322(21)$ & $435(23)$ \\
\hline $21-40$ & $542(35)$ & $846(44)$ \\
\hline$>40$ & $205(13)$ & $331(17)$ \\
\hline \multicolumn{3}{|l|}{ Status at end of follow-up } \\
\hline Lost to follow-up before age 90 & $44(3)$ & $44(2)$ \\
\hline $\begin{array}{l}\text { Censored at age } 90 \text { and later lost to } \\
\text { follow-up }\end{array}$ & $0(0)$ & $2(0.1)$ \\
\hline Censored at age 90 and later died & $40(3)$ & $10 \mid(5)$ \\
\hline Censored at age 90 and still alive & $6(0.4)$ & $39(2)$ \\
\hline Died before age 90 & $900(58)$ & $1118(59)$ \\
\hline Alive and younger than age 90 & $558(36)$ & $607(32)$ \\
\hline
\end{tabular}

Abbreviation: $\mathrm{FEV}_{\mathrm{I}}=$ forced expiratory volume of air in I second.

protection is a function of cumulative dose, and that it continues for $>10$ years after cessation of exposure. In contrast, we found no evidence for protective effects against other types of cancer, indicating that the underlying biological mechanism is likely to be local rather than systemic.

Although our analysis benefited from high rates of follow-up over a prolonged period in workers with relatively high exposures to endotoxins, and also from good information on smoking habits, it had important limitations. In particular, occupational histories were incomplete, and an assumption had to be made that each subject had worked in the same mill area from the time that he/she first entered the cotton industry. The average time between the first and second examinations was 3.4 years and 95\% of workers who had a job category at both examinations had identical job categories, suggesting that at least towards the end of follow-up, job mobility was very low. In addition, it was assumed that a worker's employment in the industry ended 1 year after his/her 
Table 3 Mortality of cohort by cause, 1966-2007

\begin{tabular}{|c|c|c|c|c|c|c|c|c|c|}
\hline \multirow[b]{2}{*}{ Cause of death } & \multicolumn{3}{|c|}{ Men } & \multicolumn{3}{|c|}{ Women } & \multicolumn{3}{|c|}{ Both sexes } \\
\hline & $\begin{array}{l}\text { No. of } \\
\text { deaths }\end{array}$ & SMR & $95 \% \mathrm{Cl}$ & $\begin{array}{l}\text { No. of } \\
\text { deaths }\end{array}$ & SMR & $95 \% \mathrm{Cl}$ & $\begin{array}{l}\text { No. of } \\
\text { deaths }\end{array}$ & SMR & $95 \% \mathrm{Cl}$ \\
\hline All causes & 900 & 102 & $95-109$ & 1118 & 107 & $101-113$ & 2018 & 105 & $100-109$ \\
\hline All MNs & 223 & 92 & $81-105$ & 292 & 106 & $94-118$ & 515 & 99 & $91-108$ \\
\hline All MNs excluding MN lung & 149 & 94 & $80-110$ & 238 & 104 & $91-117$ & 387 & 100 & $90-110$ \\
\hline MN nasopharynx & 0 & 0 & - & I & 555 & - & I & 220 & - \\
\hline MN colon & 9 & 56 & $25-99$ & 30 & 128 & $86-177$ & 39 & 99 & $70-132$ \\
\hline MN rectum & 15 & 163 & $91-256$ & 12 & |4| & $72-232$ & 27 & 152 & $100-215$ \\
\hline MN liver & 2 & 74 & - & 3 & 117 & - & 5 & 95 & $30-196$ \\
\hline MN pancreas & 15 & 148 & $83-232$ & 11 & 85 & $42-143$ & 26 & 113 & $74-160$ \\
\hline MN larynx & 2 & 95 & - & 2 & 262 & - & 4 & 139 & - \\
\hline MN lung & 74 & 89 & $70-111$ & 54 & 115 & $86-148$ & 128 & 99 & $82-116$ \\
\hline MN breast & 0 & 0 & - & 36 & 68 & $47-91$ & 36 & 67 & $47-91$ \\
\hline Cerebrovascular disease & 96 & 121 & $98-147$ & 143 & 105 & $88-123$ & 239 & 111 & $97-125$ \\
\hline Respiratory system disease & 132 & 113 & $94-133$ & 153 & 118 & $100-137$ & 285 & 115 & $102-129$ \\
\hline Bronchitis, emphysema and other COPD & 55 & 97 & $73-125$ & 57 & 149 & $113-190$ & 112 & 118 & $97-|4|$ \\
\hline Asthma & 3 & 168 & - & 2 & 52 & - & 5 & 89 & $28-185$ \\
\hline Byssinosis & 15 & 92879 & $51823-145829$ & 7 & 22410 & $8883-42085$ & 22 & 46427 & $29052-67854$ \\
\hline
\end{tabular}

Abbreviations: $\mathrm{Cl}=$ confidence interval; $\mathrm{COPD}=$ chronic obstructive pulmonary disease; $\mathrm{MN}=$ malignant neoplasm; $\mathrm{SMR}=$ standardised mortality ratio. Cls not presented where there were $<5$ cases.

Table 4 Mortality from lung cancer during 1966 to 2007 by smoking habits and years worked in the cotton industry

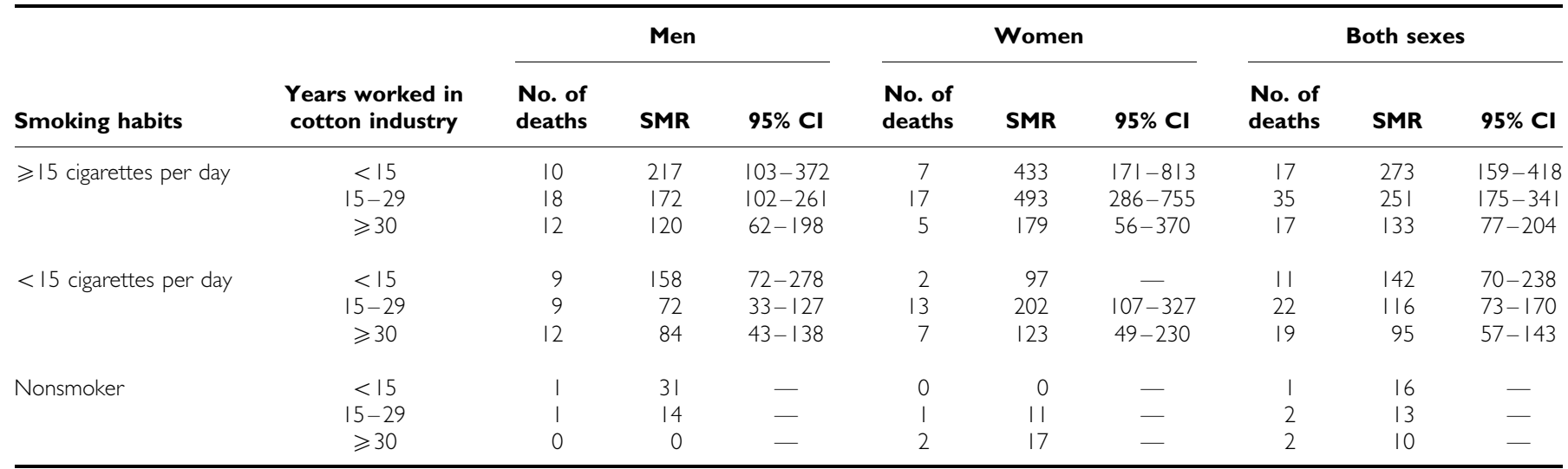

Abbreviations: $\mathrm{Cl}=$ confidence interval; SMR $=$ standardised mortality ratio. Cls not presented where there were $<5$ cases. Former smokers excluded because of small numbers ( $n=2$ deaths).

last clinical examination for workers whose leaving date had not been recorded. The last approach, which was also adopted in an earlier analysis (Hodgson and Jones, 1990), seemed reasonable as: (1) the intervals between successive visits by the research team were in the order of only 2 to 3 years, and (2) the UK cotton industry was in rapid decline by 1974 (the year of the last visit to a worker) with few mills surviving long beyond this (Hodgson and Jones, 1990).

There were also uncertainties in the retrospective quantitative assessment of endotoxin exposure levels. No direct measurements of endotoxins were available for the mills studied. Dust measurements had been made at a subgroup of 11 participating mills at around the time of the clinical examinations, using high-volume sampling over long averaging times (Fox et al, 1973a,b). However, the data generated were too sparse and too variable for generalisation to the other 41 mills. Nor were there data on potential determinants of dust concentrations, which might have enabled modelling of levels in other mills. Thus, it was not feasible to estimate endotoxin levels by combining the cohort-specific data on dust levels with findings from other studies that had measured dust and endotoxins in parallel.

Instead, endotoxin concentrations had to be extrapolated from measurements (mostly fairly recent) made elsewhere, including in other countries. No account could be taken of the source of the cotton that was handled (endotoxin levels vary by country of origin; Lane et al, 2004), and there were limited data on time trends in cotton dust levels over time.

However, it seems unlikely that misclassification of exposure would have led to a spurious inverse relation to the risk of lung cancer. If anything, the misclassification would be expected to obscure true associations (Armstrong, 1998; Heederik and Attfield, 2000). Notably, the relationship between endotoxins and lung 
Table 5 Modelled risk of death from lung cancer by smoking habits at recruitment and estimated cumulative exposure to endotoxins

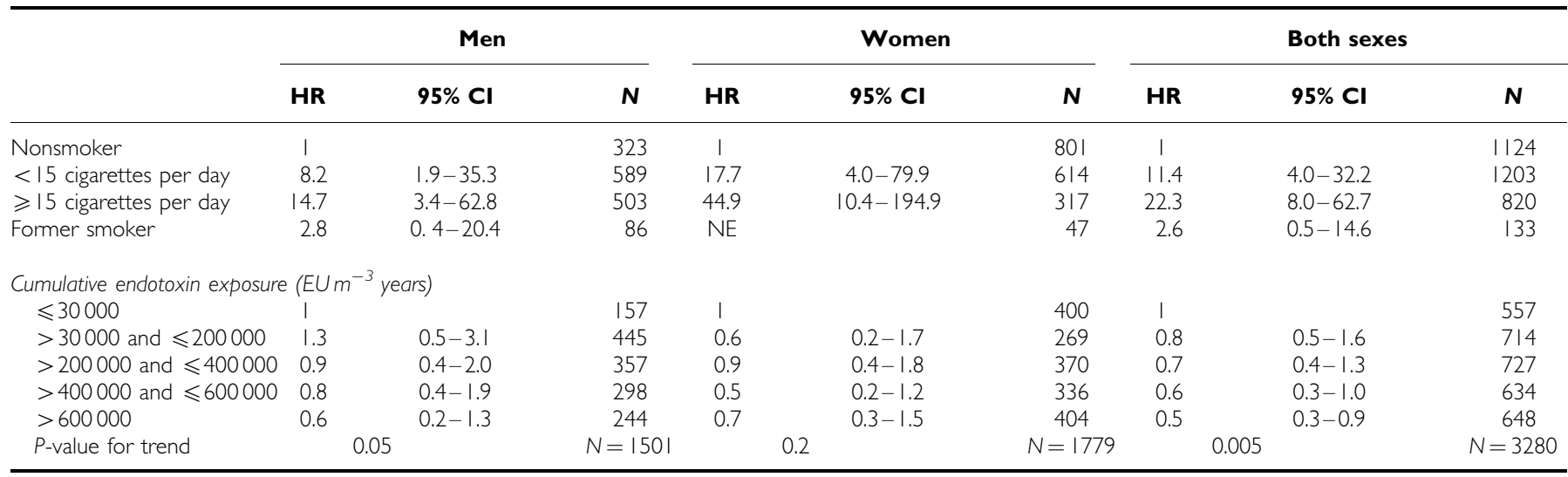

Abbreviations: $\mathrm{HR}=$ hazard ratio, $\mathrm{N}=$ number of cases; $\mathrm{NE}=$ not estimable; $\mathrm{Cl}=$ confidence interval. Analysis was based on 3280 subjects after exclusion of those ( $n=179$ ) whose work area was unknown. P-value for trend calculated using each individual subject's exposure as a covariate in the model.

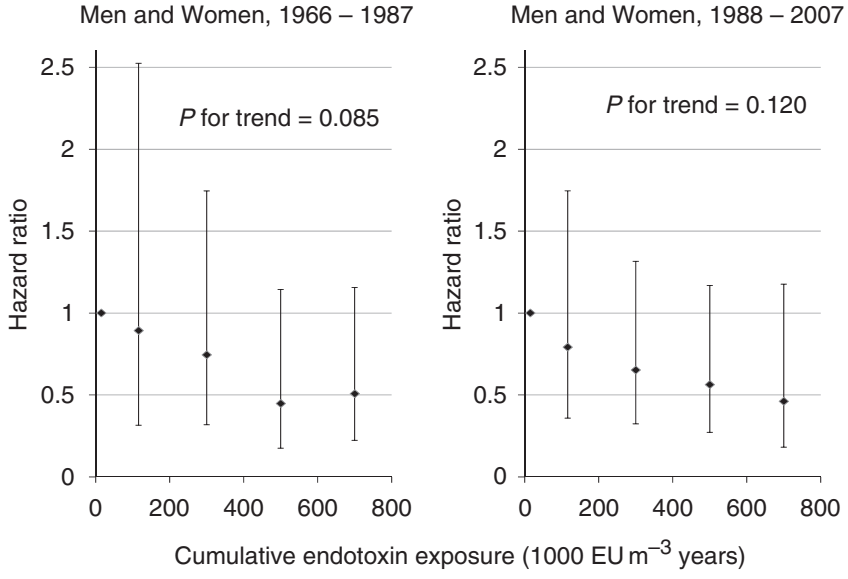

Figure I Modelled risk of death from lung cancer during 1966-1987 and 1988-2007 by estimated cumulative exposure to endotoxins. All risk estimates are adjusted for smoking habits classified as in Table 5. Bars represent $95 \%$ confidence intervals.

cancer was supported by a similar finding for duration of employment in the cotton industry, which did not rely on any assumptions about endotoxin concentrations. Sensitivity analyses revealed that increasing or decreasing the 'opening' mill area endotoxin measurements by a factor of two did not appreciably alter the results. Moreover, no similar association was apparent for the combination of cancers other than of the lung.

Ideally, our analysis would have taken into account the fact that part of each cohort member's work in the cotton industry and exposure to endotoxins occurred after his/her entry to follow-up. However, for the large majority of subjects, exposures after entry to follow-up were small in comparison with those accumulated earlier. Given the other approximations in the analysis, refinements to allow for continuing exposure during follow-up were not judged worthwhile. In support of this decision, the inverse relation between endotoxins and lung cancer remained when analysis was restricted to deaths occurring after 1987 (Figure 1), when all follow-up was after presumed last exposure.

Another possible source of error was healthy worker selection. Apart from any relation to cancer, cotton dust is a proven cause of the disabling respiratory disease, byssinosis. It is conceivable that the severity of byssinotic symptoms and disability is increased by smoking, and that as a consequence, workers who smoked were more likely to have left the cotton industry if they also had high cumulative exposure to cotton dust and therefore a greater risk of byssinosis. If so, the surviving population of workers with high exposure to cotton dust might have a lower prevalence of smoking than other cohort members, leading to spuriously low risks of lung cancer. Against this, however, the low risk of lung cancer with high exposure to endotoxins was observed after adjustment for smoking. Furthermore, after additional adjustment for baseline lung function and report of cough or phlegm, the trend was even stronger.

There is no reason why the relation between endotoxin exposure and subsequent mortality from lung cancer should be systematically different in the $10 \%$ of eligible subjects who declined to take part in the original surveys of respiratory disease, and therefore this incomplete participation would not be expected to bias comparisons of lung cancer risk according to endotoxin exposure. Similarly, the exclusion of workers of non-Caucasian ethnicity would not have biased comparisons of mortality internal to the cohort, although it limits the confidence with which findings can be generalised to non-Caucasian ethnic groups.

There is a possibility that when cohorts are followed towards maturity, incomplete ascertainment of deaths could lead to important underestimation of mortality rates at the oldest ages. To address this potential source of bias, we opted to censor all follow-up at age 90 years.

Mortality overall, and particularly from circulatory and respiratory disease, was higher than expected from national rates. Several factors may have contributed to this. First, part of the excess of respiratory disease was explained by 22 deaths from byssinosis - a direct consequence of work with cotton. There may also have been other deaths from byssinosis that were incorrectly ascribed to chronic obstructive pulmonary disease. Second, with such long follow-up, the lower-than-expected mortality from cardiovascular and respiratory disease that is normally seen in occupational cohorts because of a healthy worker effect tends to disappear. Third, the prevalence of smoking among female cohort members was relatively high (Table 2 ).

This high rate of smoking may also explain why despite their exposure to endotoxins, the overall SMR for lung cancer in women from the cohort was elevated (SMR 115, 95\% CI: 86-148). However, when adjustment was made for smoking, a clear reduction in risk of lung cancer was seen with longer employment in the cotton industry and with higher cumulative exposure to endotoxins.

This observation is consistent with those from other cohort studies, which have indicated low rates of lung cancer in cotton textile workers overall, or in those with the highest or longest exposures to dust or endotoxins (Henderson and Enterline, 1973; 
Merchant and Ortmeyer, 1981; Hodgson and Jones, 1990; Szeszenia-Dabrowska et al, 1999; Wernli et al, 2003; Laakkonen et al, 2006; Kuzmickiene and Stukonis, 2007; Mastrangelo et al, 2008). The finding has not been universal (Buiatti et al, 1979; Koskela et al, 1990; Fritschi et al, 2004; Kuzmickiene et al, 2004), but it is supported by case-control studies (Lenters et al, 2010), and in a recent systematic review and meta-analysis, the summary relative risk of lung cancer in textile workers was 0.72 (95\% CI: 0.57-0.90) (Lenters et al, 2010). Moreover, experimental studies in animals and limited trials in humans have indicated that endotoxins can induce antitumoural or cytotoxic responses (Reisser et al, 2002).

As well as adding to the evidence that endotoxins in cotton dust reduce the risk of lung cancer, our study suggests that the protective effect is restricted to lung tumours, depends on cumulative dose and persists after cessation of exposure - the low risk of lung cancer was clearly apparent in follow-up after 1987, at least 10 years after the large majority of cohort members would have last worked in the cotton industry. This pattern of findings would be compatible with a local protective mechanism in the lung acting at an early stage in carcinogenesis, or with the induction of an antitumour response, which once established continues even when there is no further exposure.

In light of these observations, there may be value in a study of biomarkers of immune and inflammatory response in the lungs of both current and former cotton mill workers when compared with unexposed controls.

\section{ACKNOWLEDGEMENTS}

This study was supported in part by a grant from the Colt Foundation (contract number CF/05/07). We thank Pauline Wall and her colleagues at the National Health Service Information Centre for their assistance with the follow-up; Sharon Maxwell and colleagues from Westlakes Scientific Consulting for their audit and coding of death certificate data; and Elaine Brown and colleagues at the Health and Safety Executive (HSE) for their expert oversight of the transfer of files from HSE to the study team. We also thank Nadi Bakirci, Rob Niven, Marcus Oldenburg, Torben Sigsgaard, Harvey Checkoway and George Astrakianakis who kindly provided us with endotoxin and dust measurements from their surveys. We thank Dan Dedman for carrying out an independent check on the statistical modelling. Finally, we acknowledge the very helpful comments of one of the reviewers.

Supplementary Information accompanies the paper on British Journal of Cancer website (http://www.nature.com/bjc)

\section{REFERENCES}

Armstrong BG (1998) Effect of measurement error on epidemiological studies of environmental and occupational exposures. Occup Environ Med 55(10): 651-656

Astrakianakis G, Seixas N, Camp J, Smith TJ, Bartlett K, Checkoway H (2006) Cotton dust and endotoxin exposure levels in three Shanghai textile factories: a comparison of samplers. J Occup Environ Hyg 3(8): 418 427

Astrakianakis G, Seixas NS, Ray R, Camp JE, Gao DL, Feng Z, Li W, Wernli KJ, Fitzgibbons ED, Thomas DB, Checkoway H (2007) Lung cancer risk among female textile workers exposed to endotoxin. J Natl Cancer Inst 99(5): $357-364$

Bakirci N, Kalaca S, Francis H, Fletcher AM, Pickering CAC, Tumerdem N, Cali S, Oldham L, Niven R (2007) Natural history and risk factors of early respiratory responses to exposure to cotton dust in newly exposed workers. J Occup Environ Med 49(8): 853

Berry G, McKerrow CB, Molyneux MKB, Rossiter CE, Tombleson JBL (1973) A study of the acute and chronic changes in ventilatory capacity of workers in Lancashire cotton mills. Br J Ind Med 30(1): 25-36

Buiatti E, Baccetti S, Cecchi F, Tomassini A, Dolara P (1979) Evidence of increased lung cancer rate among textile workers. Med Lav 70(1): 21-23

Chang C-K, Astrakianakis G, Thomas DB, Seixas NS, Camp JE, Ray RM, Li Gao D, Wernli KJ, Li W, Fitzgibbons ED, Vaughan TL, Checkoway H (2006) Risks of biliary tract cancer and occupational exposures among Shanghai women textile workers: a case-cohort study. Am J Ind Med 49(8): $690-698$

Cinkotai FF, Rigby A, Pickering CA, Seaborn D, Faragher E (1988) Recent trends in the prevalence of byssinotic symptoms in the Lancashire textile industry. Br J Ind Med 45(11): $782-789$

Cotes JE (1968) Lung Function: Assessment and Application in Medicine, 2nd edn. Blackwell Scientific Publications: Oxford and Edinburgh

De Roos AJ, Ray R, Gao D, Wernli K, Fitzgibbons E, Ziding F, Astrakianakis G, Thomas D, Checkoway H (2005) Colorectal cancer incidence among female textile workers in Shanghai, China: a case-cohort analysis of occupational exposures. Cancer Causes Control 16(10): 1177-1188

Fishwick D, Fletcher A, Pickering C, Niven R, Faragher E (1994) Respiratory symptoms and dust exposure in Lancashire cotton and man-made fiber mill operatives. Am J Respir Crit Care Med 150(2): $441-447$

Fletcher AM (2003) A five-year long prospective study of lung function decline in Lancashire textile workers. PhD, Manchester Metropolitan University, Manchester
Fox AJ, Tombleson JBL, Watt A, Wilkie AG (1973a) A survey of respiratory disease in cotton operatives: Part 1 . Symptoms and ventilation test results. Br J Ind Med 30(1): $42-47$

Fox AJ, Tombleson JBL, Watt A, Wilkie AG (1973b) A survey of respiratory disease in cotton operatives: Part II. Symptoms, dust estimations, and the effect of smoking habit. Br J Ind Med 30(1): 48-53

Fritschi L, Lakhani R, Nadon L (2004) Cancer incidence in textile manufacturing workers in Australia. J Occup Health 46(6): 493-496

Gold LS, De Roos AJ, Ray RM, Wernli K, Fitzgibbons ED, Gao DL, Astrakanakis G, Feng Z, Thomas D, Checkoway H (2006) Brain tumours and occupational exposures in a cohort of female textile workers in Shanghai, China. Scand J Work Environ Health 32: 178-184

Heederik D, Attfield M (2000) Characterization of dust exposure for the study of chronic occupational lung disease: a comparison of different exposure assessment strategies. Am J Epidemiol 151(10): $982-990$

Henderson V, Enterline PE (1973) An unusual mortality experience in cotton textile workers. J Occup Med 15(9): 717-719

Hodgson JT, Jones RD (1990) Mortality of workers in the British cotton industry in 1968-1984. Scand J Work Environ Health 16: 113-120

Koskela RS, Klockars M, Järvinen E (1990) Mortality and disability among cotton mill workers. Br J Ind Med 47(6): 384-391

Kuzmickiene I, Didziapetris R, Stukonis M (2004) Cancer incidence in the workers cohort of textile manufacturing factory in Alytus, Lithuania. J Occup Environ Med 46(2): 147-153

Kuzmickiene I, Stukonis M (2007) Lung cancer risk among textile workers in Lithuania. J Occup Med Toxicol 2(1): 14

Laakkonen A, Kyyrönen P, Kauppinen T, Pukkala EI (2006) Occupational exposure to eight organic dusts and respiratory cancer among Finns. Occup Environ Med 63(11): 726-733

Lane SR, Nicholls PJ, Sewell RDE (2004) The measurement and health impact of endotoxin contamination in organic dusts from multiple sources: focus on the cotton industry. Inhal Toxicol 16(4): 217-229

Lenters V, Basinas I, Beane-Freeman L, Boffetta P, Checkoway H, Coggon D, Portengen L, Sim M, Wouters I, Heederik D, Vermeulen R (2010) Endotoxin exposure and lung cancer risk: a systematic review and metaanalysis of the published literature on agriculture and cotton textile workers. Cancer Causes Control 21(4): 523-555

Li W, Ray RM, Gao DL, Fitzgibbons ED, Seixas NS, Camp JE, Wernli KJ, Astrakianakis G, Feng Z, Thomas DB, Checkoway H (2006a) Occupational risk factors for nasopharyngeal cancer among female textile workers in Shanghai, China. Occup Environ Med 63(1): 39-44 
Li W, Ray RM, Gao DL, Fitzgibbons ED, Seixas NS, Camp JE, Wernli KJ, Astrakianakis G, Feng Z, Thomas DB, Checkoway H (2006b) Occupational risk factors for pancreatic cancer among female textile workers in Shanghai, China. Occup Environ Med 63(12): 788-793

Liebers V, Brüning T, Raulf-Heimsoth M (2006) Occupational endotoxinexposure and possible health effects on humans (review). Am J Ind Med 49(6): $474-491$

Liebers V, Raulf-Heimsoth M, Brüning T (2008) Health effects due to endotoxin inhalation (review). Arch Toxicol 82(4): 203-210

Lundin JI, Checkoway H (2009) Endotoxin and cancer. Environ Health Perspect 117(9): 1344-1350

Mastrangelo G, Fadda E, Rylander R, Milan G, Fedeli U, Rossi di Schio M, Lange JH (2008) Lung and other cancer site mortality in a cohort of Italian cotton mill workers. Occup Environ Med 65(10): 697-700

Merchant JA, Ortmeyer C (1981) Mortality of employees of 2 cotton mills in North Carolina. Chest 79(4): S6-S11

Molyneux MKB, Tombleson JBL (1970) An epidemiological study of respiratory symptoms in Lancashire mills, 1963-66. Br J Ind Med 27(3): 225-234

Niven RM (1993) Endotoxin, microbial and cotton dust exposure as aetiological factors for respiratory symptoms in Lancashire textile workers. PhD, University of Manchester, Manchester

Oldenburg M, Latza U, Baur X (2007) Exposure-response relationship between endotoxin exposure and lung function impairment in cotton textile workers. Int Arch Occup Environ Health 80(5): $388-395$

Ray RM, Gao DL, Li W, Wernli KJ, Astrakianakis G, Seixas NS, Camp JE, Fitzgibbons ED, Feng Z, Thomas DB, Checkoway H (2007) Occupational exposures and breast cancer among women textile workers in Shanghai. Epidemiology 18(3): 383
Reisser D, Pance A, Jeannin J-F (2002) Mechanisms of the antitumoral effect of lipid A. BioEssays 24(3): 284-289

Roach SA, Schilling RSF (1960) A clinical and environmental study of byssinosis in the Lancashire cotton industry. Br J Ind Med 17(1): 1 -9

Rylander R (2002) Review: Endotoxin in the environment-exposure and effects. J Endotoxin Res 8(4): $241-252$

Simpson JCG, Niven RM, Pickering CAC, Oldham LA, Fletcher AM, Francis HC (1999) Comparative personal exposures to organic dusts and endotoxin. Ann Occup Hyg 43(2): $107-115$

Szeszenia-Dabrowska N, Wilczynska U, Strzelecka A, Sobala W (1999) Mortality in the cotton industry workers: results of a cohort study. Int J Occup Med Environ Health 12(2): $143-158$

Tom BDM, Farewell VT (2009) Statistical methods for individual-level data in cohort mortality studies of rheumatic diseases. Commun Stat-Theor M 38: $3472-3487$

Venables WN, Smith DM (2010) An Introduction to R. Published online at http://cran.r-project.org/doc/manuals/R-intro.html (accessed 11 February 2010)

Wernli KJ, Fitzgibbons ED, Ray RM, Gao DL, Li W, Seixas NS, Camp JE, Astrakianakis G, Feng Z, Thomas DB, Checkoway H (2006) Occupational risk factors for esophageal and stomach cancers among female textile workers in Shanghai, China. Am J Epidemiol 163(8): 717-725

Wernli KJ, Ray RM, Gao DL, Thomas DB, Checkoway H (2003) Cancer among women textile workers in Shanghai, China: overall incidence patterns, 1989-1998. Am J Ind Med 44(6): 595-599

Wong E, Ray R, Gao D, Wernli K, Li W, Fitzgibbons E, Feng Z, Thomas D, Checkoway H (2006) Reproductive history, occupational exposures, and thyroid cancer risk among women textile workers in Shanghai, China. Int Arch Occup Environ Health 79(3): 251-258

This work is published under the standard license to publish agreement. After 12 months the work will become freely available and the license terms will switch to a Creative Commons Attribution-NonCommercial-Share Alike 3.0 Unported License. 